\title{
History matters: the long-term impact of historical immigrant size on current xenophobia in Japan
}

\author{
Shun Gong ${ }^{1}$ and Senhu Wang ${ }^{2^{*}}$ (D)
}

\author{
* Correspondence: sw768@cam.ac. \\ uk \\ ${ }^{2}$ Department of Sociology, \\ University of Cambridge, 16 Mill \\ Lane, Cambridge CB2 1SB, UK \\ Full list of author information is \\ available at the end of the article
}

\begin{abstract}
Many studies have addressed how current immigrant size affects the strength of xenophobia from the perspectives of intergroup contact and ethnic competition theories. Can native residents' current xenophobia be explained by historical immigrant size? To explore this question, we use historical immigrant size and a survey dataset to investigate the long-term effects of historical immigrant size on current xenophobia in Japan. The results show that historical immigrant size increases current xenophobia in Japan, which may be due to previous negative contact experiences between immigrants and native residents, and the negative effects persist. The implications of these findings for our understanding of the relationship between immigrant size and xenophobia are discussed.
\end{abstract}

Keywords: Historical immigrant size, Xenophobia, Cultural persistence, Japan

\section{Introduction}

Several variables have been investigated to account for native residents' xenophobia or ethnic antagonism (Bonacich 1972; Quillian 1995). Since Quillian's (1995) first crossnational empirical study of immigrant size and xenophobia, a considerable body of scholarship has suggested that immigrant size significantly affects xenophobia (Scheepers et al. 2002; Dancygier and Donnelly 2013; Kunovich 2017; Quillian 1995). Previous scholars have proposed two main theories to explain this relation. Contact theory proposes that positive contact reduces unfavorable attitudes toward immigrants and that a higher percentage of immigrants would strengthen the effects of positive contact (Allport 1954). In contrast, ethnic competition theory contends that the growth of immigrant size increases xenophobic reactions to immigrants because of the competition for scarce resources and the perception of cultural threats from this population, which is referred to as the negative contact effect (Levitt and Nadya Jaworsky 2007; Scheepers et al. 2002).

However, the relationship between historical immigrant size and xenophobia has not been explored. Most importantly, the existing literature has neglected the aspect of cultural persistence. For instance, parents' culture preference (i.e., xenophobia)

(c) The Author(s). 2021 Open Access This article is licensed under a Creative Commons Attribution 4.0 International License, which permits use, sharing, adaptation, distribution and reproduction in any medium or format, as long as you give appropriate credit to the original author(s) and the source, provide a link to the Creative Commons licence, and indicate if changes were made. The images or other third party material in this article are included in the article's Creative Commons licence, unless indicated otherwise in a credit line to the material. If material is not included in the article's Creative Commons licence and your intended use is not permitted by statutory regulation or exceeds the permitted use, you will need to obtain permission directly from the copyright holder. To view a copy of this licence, visit http://creativecommons.org/licenses/by/4.0/. 
certainly influences that of their children. Testing the association between historical immigrant size and current xenophobia is important and could deepen our understanding of how native residents' xenophobia originated.

Japan is an ideal case for separating the effects of historical and current immigrant sizes because of its unique immigration history. Immigration in Japan is distinct not only in the distribution of immigrants by region but also in the composition of immigrants with respect to the country of origin before and after the 1990s. Using both historical and contemporary datasets, for the first time, we analyze the relationship between historical immigrant size and current xenophobia.

This paper is structured as follows. First, we review previous studies investigating historical immigrant sizes and propose our hypotheses. Then, we analyze data from the Public Opinion Poll on Internationalization and Citizens' Political Participation Survey and Japan Census data to evaluate how historical immigrant size affects current Japanese attitudes toward immigrants. Finally, we discuss how our results contribute to previous studies.

\section{Conceptual framework}

\section{Positive versus negative contact}

A substantial body of research has examined the effects of relative immigrant group size on native residents' discrimination, prejudice, and xenophobia toward immigrants or ethnic minorities (Schneider 2008; Allport 1954; Quillian 1995; Scheepers et al. 2002; Dancygier and Donnelly 2013). Previous studies investigating immigrant size and xenophobia are mainly based on the following two perspectives: the positive contact perspective based on the contact theory and the negative contact perspective based on the ethnic competition theory (Allport 1954; Scheepers et al. 2002; Levitt and Nadya Jaworsky 2007).

According to the contact theory, positive intergroup contact reduces xenophobia toward outgroup members (Allport 1954). The positive contact effect can be explained by increased knowledge regarding the other group and decreased intergroup anxiety. However, positive contact can only occur under certain conditions involving an equal group status, common objectives, intergroup cooperation, and support from authorities and the norm (Allport 1954). When these conditions are met, there is a possible negative link between immigrant size and xenophobia because opportunities for positive contact between native residents and immigrants increase as the relative proportion of immigrants increases (Pettigrew 1998; Schneider 2008).

In contrast, the ethnic competition theory posits that a higher proportion of immigrants in the population increases xenophobia among native residents (Blumer 1958; Scheepers et al. 2002). Specifically, the ethnic competition literature proposes that growth in the immigrant size enhances the competition between immigrants and native residents for scarce resources and results in higher tension between out- and in-group members (Sherif and Sherif 1967; Tajfel and Turner 1979). Moreover, studies have found that competition can be both cultural and economic (Kunovich 2002; Wang and Coulter 2019; Wang and Ramsden 2018; Wang 2019b; Kunovich 2017). 
The lost synthesis of historical immigrant size and current xenophobia

The relationship between current immigrant size and xenophobia has been investigated from different perspectives (Allport 1954; Quillian 1995; Scheepers et al. 2002; Schneider 2008; Dancygier and Donnelly 2013; Kunovich 2017; Kunovich 2002; Yan et al. 2019). However, the association between historical immigrant size and xenophobia has not been explored. We hypothesize that the effects of previous positive or negative contact between immigrants and native residents could persist and affect how native residents currently view immigrants. This hypothesis is motivated by insight regarding cultural persistence based on cultural anthropological research (Boyd and Petter Richerson 1985). According to the existing literature, the core notion is that culture evolves systematically based on the relative cost and benefit of the culture; in environments where information acquisition is costly or imperfect, general cultural beliefs regarding the right actions in different situations save individuals from the cost of acquiring information, and it is more profitable for individuals to imitate behavior from a previous generation (Giuliano and Nunn 2017; Nunn 2009; Boyd and Petter Richerson 1985). Additionally, ancestors have the ability to influence their children's cultural beliefs through education and the parenting process (Bisin and Verdier 2000; Wang and Li 2019; Wang 2019a).

The idea of cultural persistence and its long-term impacts has gained support from several empirical studies (Abbott 2005; Putnam 2007; Nunn 2008; Hiers et al. 2017; Acharya et al. 2016; Harold and Fong 2017). For example, Nunn (2008) found a negative relationship between the slave trade and current economic development in South America. Acharya et al. (2016) studied the impact of slavery on contemporary American political attitudes and found that people living in regions which had more slaves in the past are more likely to be conservative. Recently, using qualitative data, sociologists Harold and Fong (2017) found that historical memory passed on by family members influences where Jewish people in Canada choose to live. Regarding xenophobic attitudes, Hiers et al. (2017) found that the relationship between historical political situations and xenophobia is significant in Europe.

Consequently, it is possible that the effects of positive or negative contact between immigrants and native residents throughout history could affect current native residents' positive or negative attitudes toward immigrants and that the positive or negative contact effects could be stronger in areas with more historical immigrants. More specifically, as shown in Fig. 1, if the previous contact between immigrants and native residents was positive, the positive effects could be stronger in areas with more historical immigrants. If this culture persists, the historical immigrant population size could be negatively associated with current xenophobia (path 1). In contrast, if the previous contact between immigrants and native residents was negative, the negative effects could be stronger in areas with more historical immigrants. If the anti-immigrant culture persists, native residents' current xenophobia could be stimulated (path 2).

\section{Was the previous contact between immigrants and native residents in Japan positive or negative?}

Although Japan is usually regarded as an ethnically homogenous country, the history of immigration in Japan began long ago (Kashiwazaki and Akaha 2006; Green and Kadoya 2015; Lie 2001). Immigration in Japan mainly occurred in the following two waves: the 


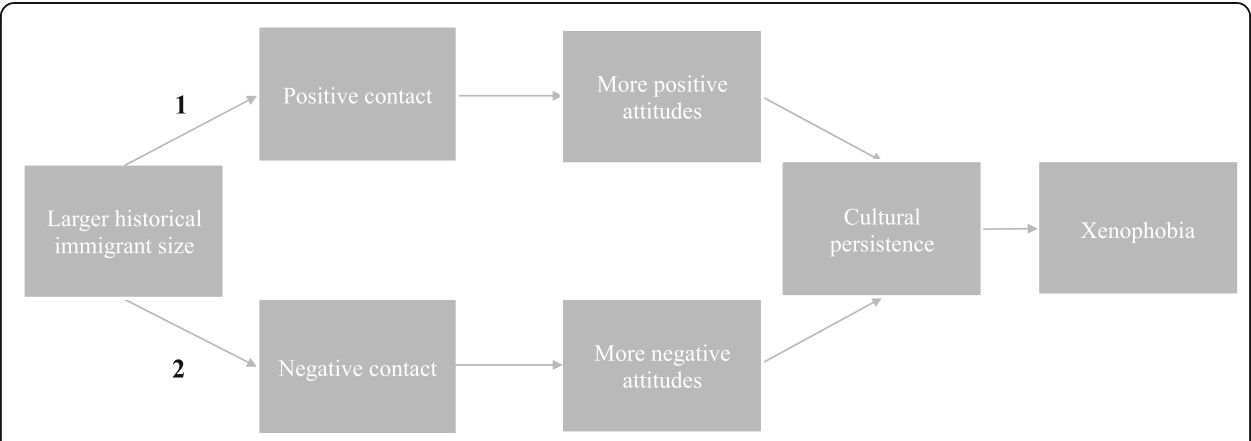

Fig. 1 Historical immigrants and current xenophobia. Source: Japan Census Data 1920-2010

arrival of pre-World War II immigrants from Japan's colonial countries and a new wave of migration since the 1990s. The first massive wave of immigrants began arriving before World War II; as early as 1930, Korean immigrants ${ }^{1}$ numbered approximately 400 , 000. The first wave of immigrants to Japan was associated with Japan's colonial history, and most immigrants arrived from Korea (Japan Census 1930). Japan had taken most of the natural and agricultural resources from its colonies, i.e., Korea and China. Among these colonies, Korea suffered the most because of its dense population. For example, the Korea Land Project in the 1910s deprived Korean farmers of most of their land, and the Korean Rice Growth Project in the 1920s sent approximately 56\% of the rice and wheat in Korea to Japan. Many Korean men had to immigrate to Japan or China to feed their families (Fukuda 1993). These immigrants were not forced to migrate to Japan and migrated voluntarily. Since 1940, because of the wartime labor shortage, Korean immigrants and some Chinese immigrants were forced to move to Japan to work in "3D" (dirty, dangerous, and demanding) jobs (Chung 2010).

After Japan lost the war in 1945, the Korean immigrants were free to return to Korea. However, because Korea experienced more severe chaos than Japan (Fukuda 1993), many Koreans chose to stay in Japan. According to the Japanese census in 1950, approximately 460,000 Korean immigrants stayed in Japan after WWII ${ }^{2}$. Chinese immigrants represented the second-largest group of historical immigrants in Japan. However, the size of this population was much smaller than that of the Korean immigrants. According to the Japanese census in 1930, there were approximately 420,000 Korean immigrants but only 40,000 Chinese immigrants in Japan. The immigration policy during the colonial period was exclusive to immigrants. The massacre of Korean immigrants during the Great Kanto earthquake in 1923 fully illustrates the logic of Japan's immigration policy during the colonial period. After WWII, with the signing of the 1952 Treaty of Peace with Japan in San Francisco, Japan's new immigration policy was established. The law established the framework for Japan's postwar immigration policy, which did not encourage further settlement (Ryang 2002; Araragi 2008).

The immigration policy did not change until the 1980s, when the internal migration strategy, which was implemented in the 1960s, could not fill the labor shortage (Lie

\footnotetext{
${ }^{1}$ Since North and South Korea has not been divided into two states until 1945, Korean immigrants before 1945 refer to immigrants from Korea Peninsula.

${ }^{2}$ Some researchers report that there were approximately 2 million Korean immigrants in the 1940s (Chung 2010).
} 
2001). As a result, Japan reopened its doors to immigrants and established its new immigration order by passing a new immigration law in 1989 (Cornelius and Tsuda 2004). The new immigration law is remarkably open to skilled immigrants; however, unskilled immigrants are not welcome, and less-skilled immigrants can only enter through the so-called side door or back door (Takenoshita 2013; Gong 2018; Holbrow and Nagayoshi 2016). For example, Japan's immigration law accepts less-educated "Nikkeijin," i.e., individuals with Japanese ancestors, as unskilled immigrants. Other unskilled immigrants who lack this special relationship with Japan can only enter through the guest-worker program, which offers 5-year visas and far lower salaries than those received by their Japanese counterparts (Kondo 2002). The immigration policy in the new wave is still exclusive to immigrants.

The following question to be discussed pertains to the definition of current and historical immigrants in Japan. As previously mentioned in the discussion of Japan's immigration policy, we consider immigration before the 1990s historical immigration and immigration post-1990s current immigration. To identify the descriptive distributions of immigrants in Japan by year, we obtained data from Japan's Census and depicted the changes in historical and current immigration by year $^{3}$. As shown in Fig. 2, since the 1990s, immigration in Japan grew more quickly than before. Furthermore, the composition of the pre- and post-1990 immigrant populations in Japan differs. Pre-1990 immigration, which we call historical immigration, comprised immigrants primarily from Korea, who began arriving as early as 1930 (Araragi 2008). However, Chinese immigrants predominated after the 1990s, and in the 2000s, Chinese immigrants replaced Korean immigrants as the largest foreign-born group in Japan. These distributions confirm that our definition of historical and current immigration by the 1990s is appropriate.

Was the contact between historical immigrants and native residents in Japan positive or negative? Divergent studies have revealed that the previous contact relationship between immigrants and native residents was negative. First, positive contact can only occur when immigrants and native residents have an equal group status, common objectives, intergroup cooperation, and support from authorities and the norm (Allport 1954). However, as previously mentioned, historical immigrants in Japan originated from Japan's colonies, and these immigrants are considered second class citizens that could solve the labor shortage in Japan. All conditions proposed by the positive contact theory are not possible; thus, positive contact is impossible according to the definition.

Second, naturalization is a strong indicator of the relationship between historical immigrants and native resident because if immigrants cannot naturalize or are unwilling to naturalize, the contact is more likely to be negative. The existing literature shows that the naturalization rate of historical immigrants in Japan is extremely low. For example, as shown in Table 1, Korean immigrants, representing one of the main historical immigrant groups in Japan, have a low naturalization rate. In addition, Chung (2010) found that Japan's naturalization rate is the lowest

\footnotetext{
${ }^{3}$ Because the early wave of the Japan Census does not provide details regarding the countries from which the immigrants originates, except for China and Korea, we cannot include information regarding the number of immigrants from other countries (for details, see the Statistics Bureau of Japan). In addition, we do not have information regarding other ethnic minority groups, such as Burakumin and Okinawans.
} 


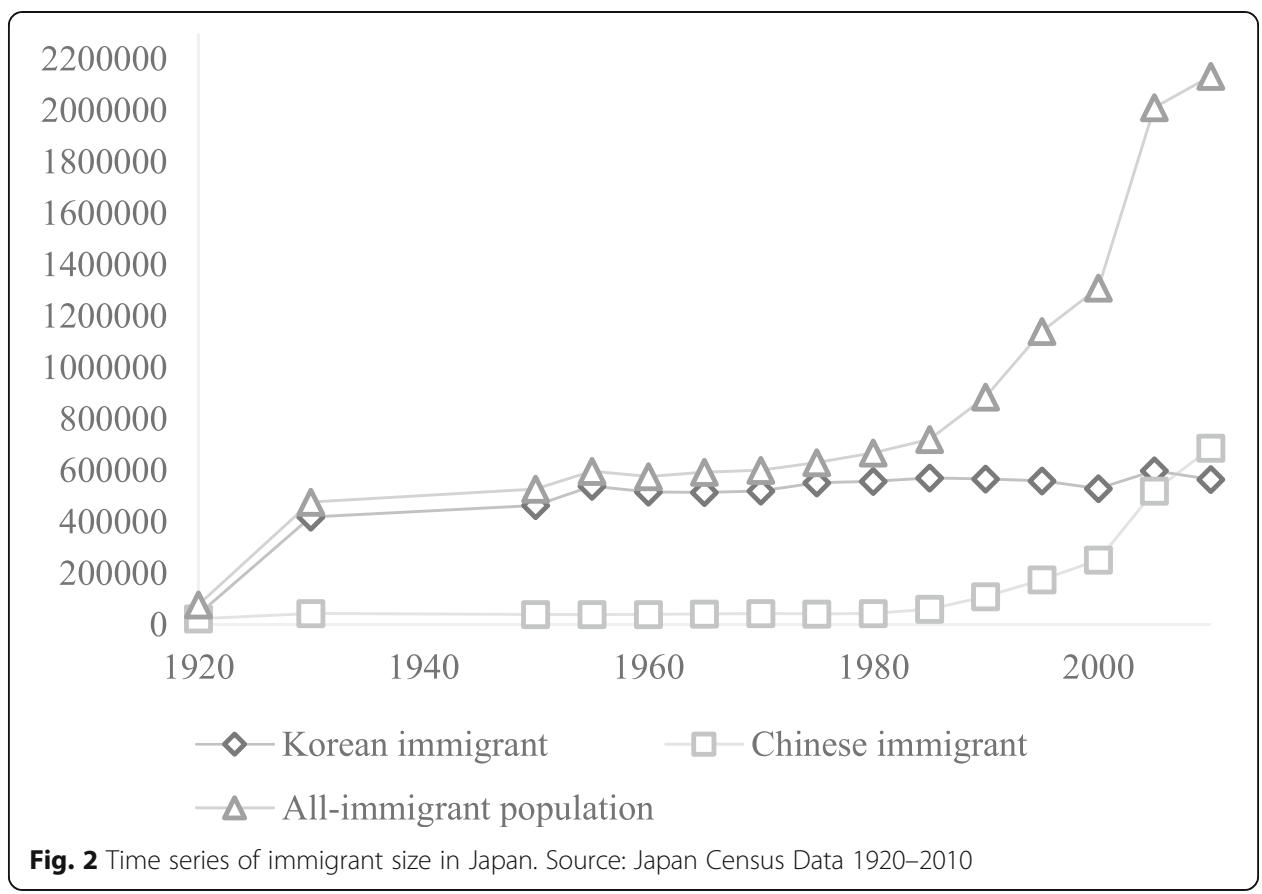

among conservative jus sanguinis citizenship countries and that "Japan is the only country with low rates of naturalization across generations of foreign residents" (Chung 2010, p. 47); even most third- and fourth-generation Koreans remain foreign residents of Japan. The results show that historical immigrants cannot or are reluctant to assimilate in Japan, suggesting that a negative intergroup relationship previously existed between immigrants and native residents.

Thus, we hypothesize the following:

Hypothesis: Historical immigrant size in Japan is positively related to current xenophobia.

Table 1 Annual naturalizations in Japan

\begin{tabular}{lll}
\hline Year & Korean immigrants & Total \\
\hline 1952 & 232 & 282 \\
1955 & 2434 & 2661 \\
1960 & 3763 & 4156 \\
1965 & 3438 & 4188 \\
1970 & 4646 & 5379 \\
1975 & 6323 & 8568 \\
1980 & 5987 & 8004 \\
1985 & 5040 & 6824 \\
1990 & 5216 & 6794 \\
1995 & 10,321 & 14,104 \\
2000 & 9842 & 15,812 \\
2005 & 9689 & 15,251 \\
\hline
\end{tabular}

Source: Chung 2010; Ministry of Justice 1986-2008 


\section{Data and measures \\ Data}

We employ data from a Japanese census dataset from 1920 to 2010 to show the macrolevel historical and current immigrant proportions. The Japan census was conducted from 1920 to 2015. The early waves of the Japan census conducted before 1950 were measured at 10-year intervals, but because of WWII, a 1940 census survey was not conducted. After 1950, similar to most census data, Japan census data were collected at 5year intervals. Regarding the composition of the immigrant populations, all sets of data show overall foreign-born, Korean and Chinese immigrant sizes by prefecture in Japan. We use the proportions of immigrants in the 1920, 1930, 1950, 1955, 1960, 1965, 1975, 1980, and 1985 datasets as our historical immigrant sizes because the new immigration law came into effect in 1989. In addition, to match our individual data obtained in 2013, the current proportion of immigrants by prefecture is calculated from the Japan census data in 2010. Finally, to control for the macro-level economic situation in the regions, the industrial composition in different regions in 2010 is considered in our dataset.

To obtain individual-level data, a survey, such as the Japan General Social Survey (JGSS) (which is similar to GSS in the United States), that includes respondents from all Japanese prefectures is ideal. However, since the JGSS does not provide any information to the public or researchers about where the respondents resided (for details, see http://jgss.daishodai.ac.jp/english/data/dat_top.html), we had to obtain another dataset including not only Japanese xenophobic attitudes but also the place of residence. The data derived from the Public Opinion Poll on Internationalization and Citizens' Political Participation Survey 2013 are superior to other datasets because such data include several dimensions of xenophobia; all questions related to xenophobic attitude factors were used as control variables in our data analysis. Most importantly, the survey includes specific information regarding the prefectures in which the respondents live.

The survey was conducted in 2013. The respondents' ages ranged from 20 to 80 years, and all respondents held a Japanese nationality. The survey collected data from a stratified random sample. First, 51 municipalities, which are regional-level administrative divisions smaller than a prefecture in Japan, were selected using stratified random sampling methods based on the rates of immigration. Specifically, according to the proportion of immigrants based on the 2010 Japan Census, three categories $^{4}$ were used in the random sampling of the regions (Tanabe 2016). Second, 200 cases were randomly chosen from each region. The survey was conducted by mail, and the response rate was $42.2 \%$.

The sampling procedures ensured that our data include areas with both high and low immigrant rates, rendering the survey nationally representative. However, because we do not have data regarding historical immigrants in all 51 municipalities, we must analyze our data at the prefecture level. The 51 municipalities belong to 28 prefectures $^{5}$ in Japan.

\footnotetext{
${ }^{4}$ Municipalities with more than the national average value (1.3\%), those with values ranging from half of the national average $(0.68 \%)$ to the national average $(1.3 \%)$, and those with less than half of the national average value $(0.68 \%)$

${ }^{5}$ Aichi, Akita, Aomori, Chiba, Fukui, Fukushima, Hiroshima, Hokkaido, Hyogo, Ibaraki, Iwate, Kanagawa, Kyoto, Mie, Miyagi, Miyazaki, Nagasaki, Niigata, Oita, Osaka, Saitama, Shiga, Shizuoka, Tokyo, Toyama, Yamagata, Yamaguchi, and Yamanashi.
} 


\section{Measurement of xenophobia}

Xenophobia was measured with three questions assessing the respondents' views of immigration in Japan. The following questionnaire was used:

Different opinions exist about immigrants from other countries living in Japan. How much do you agree or disagree with each of the following statements?

- Immigrants are culturally threatening to Japanese culture.

- Immigrants increase the crime rates.

- Immigrants take resources away from native Japanese residents.

Participants responded to each question on a 5-point scale, with 1 representing "strongly disagree" and 5 representing "strongly agree." Higher scores indicate a more hostile attitude toward immigrants. A factor analysis was used to create a latent variable for xenophobia. The results of the factor analysis are shown in Table 2.

The independent variables include contextual-level historical and current immigrant proportions across different regions. Regarding the historical immigrant size, as previously mentioned, we use the proportions of immigrants in the 1920, 1930, 1950, 1955, 1960, 1965, 1975, 1980, and 1985 datasets as our historical immigrant sizes. However, due to space limitations, we only consider the immigration rates in 1930 (approximately 10 years before WWII), 1955 (10 years after WWII), and 1980 (approximately 10 years before Japan's new immigration policy was implemented in 1989). Finally, the current immigrant sizes are calculated based on the immigration rates across prefectures in 2010.

The control variables include gender (Female $=1$, Male $=0$ ), age, occupational status, years of residence in the current prefecture, logarithm of household income, and current ratios of manufacturing across prefectures. Information regarding gender and age was requested to obtain the respondents' demographic characteristics. Occupational status is based on the Erikson-Goldthorpe's class categories 6 (EGP 6) (Erikson et al. 1979), which was created by considering the following three aspects of the respondents' jobs: occupational title, employment status, and firm size. In our analysis, we adapted the EGP 6 classification, which includes higher professionals, lower professionals, self-employed, skilled manual workers, unskilled manual workers, and farmers. We categorized the respondents who did not currently have a job or were housewives as unemployed residents. We aimed to control for the effect of years of residence in the current region because historical immigration in a certain region is unlikely to affect those who have not lived in the area for long. Household income was recorded as

Table 2 Exploratory factor analysis results for xenophobia

\begin{tabular}{ll}
\hline Item & Factor loadings \\
\hline Cultural threat & Identification \\
Increase in crime rate & 0.62 \\
Economic threat & 0.63 \\
\% of variance & 0.5 \\
Eigenvalues & 81.6 \\
Number of test measures & 1.02 \\
\hline
\end{tabular}


a natural logarithm of the annual household income before tax deductions during the previous year. Finally, the ratios of manual labor by prefecture were calculated using the 2010 Japan census data and used as a control.

\section{Measurement and methods}

\section{OLS regression with a clustered standard error effect}

To test our hypothesis, the data were analyzed using an ordinary least squares regression (OLS) with a clustered standard error at the regional level to account for regional xenophobia clustering, which violates independence assumptions (Morgan and Winship 2014). The equation can be written as follows:

$$
Y_{i j}=\beta_{0}+\beta_{1} X_{j}+\beta_{2} X_{i j}+e_{i j}
$$

where $Y_{i j}$ denotes xenophobia of individual $i$ in region $j, X_{j}$ represents regional-level variables, such as the historical and current immigrant sizes in 2010 and other control variables at the regional level, and $X_{i j}$ represents control variables for individual $i$ at regional level $j$. Furthermore, $e_{i j}$ is the standard error at the individual level.

\section{Results}

Table 3 shows the descriptive characteristics of our variables. According to the historical immigrant populations, the overall immigration rates do not change considerably before 1985, and immigrants consistently represent less than $1 \%$ of the Japanese population, demonstrating the ethnic homogeneity in Japanese society. However, the Japan census does not record historical immigrant size in all periods; for example, we cannot determine the immigrant population between 1930 and 1950 from the census data (Chung 2010). The average years of education attained by the respondents are approximately 13 years. The residential-year variable shows that most respondents have lived in their respective prefectures for more than 30 years, suggesting that the historical immigrant population would affect their attitudes toward immigration in their regions. According to the 2010 Japan census, the average age in Japan is approximately 44.7 years. This age distribution reveals that our dataset includes more elderly than young people; thus, we must be cautious in drawing conclusions from the data.

Additionally, we find that the correlations between historical and current immigrant proportions across regions are always less than 0.2, revealing that Japan is an ideal case to analyze the effect of historical immigrant size because we separate the effects of past and current immigrant sizes with the data from Japan. In the next step, we also find the prefecture-level immigration proportions from 1920 to 2010 are significantly different. Before 1990, the historical immigrants (1920-1985) were highly concentrated in the Kansai area, whereas current immigrants (2010) are mainly concentrated near Tokyo or large cities in the Kanto area. The distributions further show that Japan is ideal for separating the effects of historical and current immigration.

Table 4 presents the results from estimation models investigating the relationship between immigrant size and current xenophobia. The first model includes only control variables; the subsequent models, shown in Table 4, are our main models. Those models systematically add historical immigrant size in 1930, 1955, and 1980 to assess the effects of historical immigrant size on xenophobia after controlling for the effect of current immigrant size. After each step, we also test the VIF (variance inflation factor) 
Table 3 Description of variables

\begin{tabular}{|c|c|c|c|c|c|}
\hline Continuous variables & $N$ & Mean & SD & Min & Max \\
\hline Xenophobia & 3963 & 0.000 & 0.757 & -1.872 & 1.726 \\
\hline Age & 4052 & 53.966 & 15.292 & 20.000 & 80.000 \\
\hline Educational years & 4027 & 13.015 & 2.214 & 9.000 & 16.000 \\
\hline Resident years & 4027 & 31.871 & 20.114 & 0.000 & 80.000 \\
\hline Logarithm of household income & 4062 & 2.601 & 2.325 & 0.000 & 9.210 \\
\hline Ratios of manufacturing in 2010 & 4062 & 0.231 & 0.049 & 0.150 & 0.316 \\
\hline Historical immigrant size 1920 & 4062 & 0.002 & 0.002 & 0.000 & 0.008 \\
\hline Historical immigrant size 1930 & 4062 & 0.008 & 0.008 & 0.001 & 0.029 \\
\hline Historical immigrant size 1950 & 4062 & 0.007 & 0.006 & 0.001 & 0.024 \\
\hline Historical immigrant size 1955 & 4062 & 0.008 & 0.007 & 0.001 & 0.025 \\
\hline Historical immigrant size 1960 & 4062 & 0.007 & 0.006 & 0.001 & 0.024 \\
\hline Historical immigrant size 1965 & 4062 & 0.006 & 0.006 & 0.001 & 0.022 \\
\hline Historical immigrant size 1970 & 4062 & 0.006 & 0.006 & 0.001 & 0.020 \\
\hline Historical immigrant size 1975 & 4062 & 0.006 & 0.006 & 0.001 & 0.020 \\
\hline Historical immigrant size 1980 & 4062 & 0.006 & 0.005 & 0.001 & 0.020 \\
\hline Historical immigrant size 1985 & 4062 & 0.006 & 0.006 & 0.001 & 0.020 \\
\hline Immigrant size 2010 & 4062 & 0.017 & 0.009 & 0.003 & 0.032 \\
\hline Categorical variables & & & \multicolumn{2}{|c|}{ Percentage (\%) } & \\
\hline High professionals & & & & 18.26 & \\
\hline Low professionals & & & & 24.77 & \\
\hline Self-employed & & & & 2.44 & \\
\hline Skilled manual workers & & & & 9.28 & \\
\hline Unskilled manual workers & & & & 11.06 & \\
\hline Agricultural laborers & & & & 1.440 & \\
\hline Jobless & & & & 32.750 & \\
\hline Share of women & & & & 52.940 & \\
\hline
\end{tabular}

to avoid multicollinearity between the historical immigration proportion and the 2010 immigration proportion.

First, regarding the current immigrant population size and xenophobic attitudes, the first model in Table 4 shows that the marginal effect of current immigrant size is positive and significant, revealing that, consistent with the prior ethnic competition literature, the current immigrant size increases native residents' xenophobia in Japan (Quillian 1995; Scheepers et al. 2002). To illustrate the ethnic competition hypothesis in detail, we further investigate how the other economic competition indicators among the control variables affect people's xenophobic attitudes. Both individuals' occupational status and manual labor ratio across regions are significant, revealing that socioeconomically disadvantaged citizens tend to be more opposed to immigration (Kunovich 2017). For example, compared to high-level professional workers, farmers are more hostile toward immigration. The effects of gender, age, and household income are not significantly related to xenophobic attitude. Educational attainment is negatively related to native residents' xenophobic attitudes, whereas years of residence in the prefecture are positively related to people's xenophobic attitudes. 
Table 4 OLS regression models of Japanese residents' xenophobia

\begin{tabular}{|c|c|c|c|c|}
\hline & 2010 & 1930 & 1955 & 1980 \\
\hline Female (ref. = male) & $-0.021(0.034)$ & $-0.022(0.033)$ & $-0.022(0.0334)$ & $-0.022(0.033)$ \\
\hline Age & $-0.002(0.001)$ & $-0.002(0.001)$ & $-0.002(0.001)$ & $-0.002(0.001)$ \\
\hline Educational years & $-0.026^{* * *}(0.007)$ & $-0.026^{* * *}(0.007)$ & $-0.026^{* * *}(0.007)$ & $-0.026^{* * *}(0.007)$ \\
\hline Resident years & $0.002^{* * *}(0.001)$ & $0.002^{* * *}(0.001)$ & $0.002^{* * *}(0.001)$ & $0.002^{* * *}(0.001)$ \\
\hline \multicolumn{5}{|c|}{ Occupational status (ref. = high professionals) } \\
\hline Low professionals & $-0.047(0.126)$ & $-0.048(0.125)$ & $-0.048(0.126)$ & $-0.049(0.126)$ \\
\hline Self-employed & $0.032(0.029)$ & $0.033(0.029)$ & $0.033(0.029)$ & $0.033(0.029)$ \\
\hline Skilled manual & $0.058(0.057)$ & $0.055(0.057)$ & $0.055(0.057)$ & $0.056(0.057)$ \\
\hline Unskilled manual & $-0.030(0.054)$ & $-0.030(0.055)$ & $-0.030(0.054)$ & $-0.030(0.054)$ \\
\hline Agricultural & $0.204^{*}(0.118)$ & $0.203^{*}(0.117)$ & $0.206^{*}(0.117)$ & $0.206^{*}(0.118)$ \\
\hline Unemployed & $0.020(0.035)$ & $0.018(0.035)$ & $0.018(0.035)$ & $0.018(0.035)$ \\
\hline Logarithm of household income & $-0.009(0.014)$ & $-0.008(0.014)$ & $-0.008(0.014)$ & $-0.008(0.014)$ \\
\hline Ratios of manufacturing in 2010 & $0.540^{*}(0.328)$ & $0.642^{* *}(0.270)$ & $0.591 *(0.291)$ & $0.580^{*}(0.296)$ \\
\hline Immigrant size 2010 & $8.067^{* * *}(1.979)$ & $6.458^{* * *}(1.698)$ & $6.874^{* * *}(1.822)$ & $6.541^{* * *}(1.975)$ \\
\hline Historical immigrant size 1930 & & $4.485^{* * *}(1.413)$ & & \\
\hline Historical immigrant size 1955 & & & $4.162^{* *}(1.538)$ & \\
\hline Historical immigrant size 1980 & & & & $4.972^{* *}(2.023)$ \\
\hline Constant & $0.145(0.155)$ & $0.110(0.159)$ & $0.120(0.156)$ & $0.131(0.154)$ \\
\hline Observations & 3155 & 3155 & 3155 & 3155 \\
\hline R-squared & 0.017 & 0.019 & 0.018 & 0.018 \\
\hline
\end{tabular}

Robust standard errors in parentheses

${ }^{* * *} p<0.01$; ${ }^{* *} p<0.05 ;{ }^{*} p<0.1$

The second model shows that even after controlling for the effects of current immigrant size, the size of the foreign-born population in 1930 is significantly and positively related to xenophobic attitude. A one-unit increase in historical immigrant size in 1930 increases one's xenophobia by $4.485(p<0.01)$. Next, the subsequent two models reveal that the historical immigrant sizes in 1955 and 1980 are also significantly and positively associated with current xenophobia. Those results suggest that, in line with ethnic competition theory, historical immigrant size has a negative effect on pro-immigration attitudes in Japan. As proposed in our hypothesis, those results might come from contact between immigrants and native residents in the past; thus, when previous contact between immigrants and native residents was negative and such culture persists, antiimmigrant attitudes could be stimulated.

\section{Possible channel: can the impact of historical immigration be explained by historical Korean or Chinese immigration?}

As shown in the review of the immigration history in Japan and the composition of the immigrant population in Japan (Fig. 2) in the previous chapter, historical immigration in Japan primarily comprised immigrants from Korea, and some immigrants arrived from China. Subsequently, we analyze how the historical foreign-born population negatively affects the acceptance of immigrants in Japan by separating the effects of previous Korean and Chinese immigration.

Similar to the previous models shown in Table 4, the models shown in Table 5 further explore the impacts of the historical proportions of the Korean and Chinese 
Table 5 OLS regression models of Japanese residents' xenophobia

\begin{tabular}{|c|c|c|c|}
\hline & 1930 & 1955 & 1980 \\
\hline Female (ref. = male) & $-0.022(0.033)$ & $-0.022(0.033)$ & $-0.022(0.033)$ \\
\hline Age & $-0.002(0.001)$ & $-0.002(0.001)$ & $-0.002(0.001)$ \\
\hline Educational years & $-0.026^{* * *}(0.007)$ & $-0.026^{* * *}(0.007)$ & $-0.026^{* * *}(0.007$ \\
\hline Resident years & $0.002^{* * *}(0.001)$ & $0.002^{* * *}(0.001)$ & $0.002^{* * *}(0.001)$ \\
\hline \multicolumn{4}{|c|}{ Occupational status (ref. = high professionals) } \\
\hline Low professionals & $-0.048(0.125)$ & $-0.048(0.125)$ & $-0.047(0.125)$ \\
\hline Self-employed & $0.033(0.029)$ & $0.033(0.029)$ & $0.033(0.029)$ \\
\hline Skilled manual & $0.056(0.057)$ & $0.055(0.057)$ & $0.055(0.057)$ \\
\hline Unskilled manual & $-0.029(0.055)$ & $-0.029(0.055)$ & $-0.029(0.055)$ \\
\hline Agricultural & $0.203^{*}(0.117)$ & $0.206^{*}(0.117)$ & $0.205^{*}(0.118)$ \\
\hline Unemployed & $0.018(0.035)$ & $0.019(0.035)$ & $0.019(0.035)$ \\
\hline Logarithm of household income & $-0.008(0.014)$ & $-0.00(0.014)$ & $-0.008(0.014)$ \\
\hline Ratios of manufacturing in 2010 & $0.662 *(0.327)$ & $0.588(0.365)$ & $0.366(0.329)$ \\
\hline Immigrant size 2010 & $6.431^{* * *}(1.766)$ & $6.900^{* * *}(2.091)$ & $7.373^{* * *}(1.960)$ \\
\hline Historical Korean immigrant size 1930 & $4.290^{* * *}(1.268)$ & & \\
\hline Historical Chinese immigrant size & $8.106(17.14)$ & & \\
\hline Historical Korean immigrant size 1955 & & $4.118^{* *}(1.589)$ & \\
\hline Historical Chinese immigrant size 1955 & & $5.801(36.34)$ & \\
\hline Historical Korean immigrant size 1980 & & & $5.739 * *(2.141)$ \\
\hline Historical Chinese immigrant size 1980 & & & $-43.94(55.94)$ \\
\hline \multirow[t]{2}{*}{ Constant } & 0.106 & 0.120 & 0.181 \\
\hline & $(0.172)$ & $(0.170)$ & $(0.156)$ \\
\hline Observations & 3155 & 3155 & 3155 \\
\hline R-squared & 0.019 & 0.018 & 0.018 \\
\hline
\end{tabular}

Robust standard errors in parentheses

${ }^{* * *} p<0.01 ;{ }^{* *} p<0.05 ;{ }^{*} p<0.1$

immigrant population sizes on current pro-immigration attitudes in Japan. Because of space limitations, we also show the Korean and Chinese immigrant population sizes and their effects on xenophobia in 1930, 1955, and 1980. The first model shown in Table 5 illustrates how immigrant population size across prefectures in 1930 affects current xenophobic attitudes, and the 1955 and 1980 models show the historical Korean and Chinese immigrant population sizes in 1955 and 1980 and their long-term effects on current xenophobia.

According to the models in Table 5, we find that although the Chinese immigrant size has not significantly affected xenophobic sentiment in Japan, the Korean immigrant size has exerted a negative impact on pro-immigration attitudes in Japan in every wave. For example, for each one-unit increase in Korean immigrant size in 1930, current xenophobia increases by $4.29(p<0.01)$, whereas Chinese immigrant size in 1930 is not significantly associated with one's current xenophobia. The results confirm that the impact of historical immigrant size on current xenophobia originates from the historical wave of Korean immigrants to Japan. Additionally, these results further confirm that the positive relation between historical immigrant size and one's current xenophobia is due to the cultural persistence of past negative contact between Japanese and Korean immigrants. 
Most controlled variables are consistent with our previous results as shown in Table 4. Ethnic competition theory effectively explains the impact of the current immigration proportion on xenophobia, and the immigrant population size in 2010 shows a significant and positive effect on current xenophobic attitudes. Gender, age, and household income are not significantly related to current xenophobia, whereas education attainment, years of residence, occupational status, and macro-level manufacturing rates are significantly related to current xenophobia.

The following question should be considered: Why are only the historical Korean immigrant sizes negatively related to current xenophobia? Is it because Chinese immigrants have more positive contact with Japanese native than Korean immigrants? To answer this question, we show the detailed composition of the historical Korean and Chinese immigrant populations in Japan by year (Table 6). Table 6 shows that the reason that historical Chinese immigrant rate does not have a significant effect might not be due to their low presence compared to Korean immigrants. For example, from 1930 to 1985 , Korean immigrants represented more than $80 \%$ of all immigrants in Japan, and the percentage even exceeded $90 \%$ in 1955. In contrast, Chinese immigrants always constituted less than $10 \%$ of all immigrants in Japan, except for in 1920, when the total immigrant size was small compared with that during subsequent periods.

\section{Robustness check: instrumental variable}

To confirm the robustness of the results for the relationship between historical Korean immigration and current xenophobia, referring to historical records, we performed instrumental regression models. The present study used the distance, measured with the Google Maps distance calculator, from regions where respondents live to Busan Port in Korea as the instrumental variable (IV) because numerous historical records show that most historical Korean immigrants to Japan departed from Busan Port in Korea (Araragi 2008). Table 7 shows the correlations between the distance to Busan and historical proportions of Korean immigrants in different regions of Japan. The results show a strong correlation between historical proportions of Korean immigrants and distance to Busan Port; however, the new wave of migration in 2010 does not show the same trend.

In addition, in the first step, we also controlled for the effect of the historical proportion of manual labor because, as proposed by the dual labor market theory, most

Table 6 Distribution of Korean and Chinese immigrants

\begin{tabular}{llllll}
\hline Year & Korean & Percentage & Chinese & Percentage & Total \\
\hline 1920 & 40,755 & 0.522 & 24,130 & 0.309 & 78,061 \\
1930 & 418,989 & 0.877 & 43,799 & 0.092 & 477,695 \\
1950 & 464,277 & 0.879 & 39,885 & 0.076 & 528,048 \\
1955 & 539,635 & 0.903 & 40,500 & 0.068 & 597,438 \\
1960 & 516,211 & 0.894 & 40,084 & 0.069 & 577,205 \\
1965 & 515,269 & 0.867 & 42,654 & 0.072 & 594,038 \\
1970 & 519,846 & 0.866 & 43,629 & 0.073 & 600,613 \\
1975 & 552,472 & 0.877 & 41,740 & 0.066 & 630,204 \\
1980 & 557,672 & 0.834 & 43,748 & 0.065 & 669,069 \\
1985 & 571,234 & 0.793 & 60,549 & 0.084 & 720,093 \\
\hline
\end{tabular}


Table 7 Correlation between past Korean immigration and distance to Busan Port

\begin{tabular}{ll}
\hline Past Korean immigration proportion & Distance to Busan Port \\
\hline Historical Korean immigrant size 1920 & -0.441 \\
Historical Korean immigrant size 1930 & -0.292 \\
Historical Korean immigrant size 1950 & -0.329 \\
Historical Korean immigrant size 1955 & -0.316 \\
Historical Korean immigrant size 1960 & -0.265 \\
Historical Korean immigrant size 1965 & -0.218 \\
Historical Korean immigrant size 1970 & -0.206 \\
Historical Korean immigrant size 1975 & -0.208 \\
Historical Korean immigrant size 1980 & -0.196 \\
Historical Korean immigrant size 1985 & -0.183 \\
Historical Korean immigrant size 2010 & -0.081 \\
\hline
\end{tabular}

historical Korean immigrants in Japan were also laborers who worked in manual industries (Doeringer and Piore 1985). Therefore, it is appropriate to assume that regions with more manual industries tend to need more immigrants.

The results of the IV regression are shown in Table 8; although the significance of Korean immigration disappears in the 1950 s, the positive effect of past Korean immigrant size remains $(p=0.11)$. For the years of 1930 and 1980, all past Korean immigration shows a significantly negative effect on present pro-immigration attitudes. The IV test confirms the robustness of our previous results.

Table 8 Regression models of Japanese residents' xenophobia (instrumented)

\begin{tabular}{llll}
\hline & 1930 & 1955 & 1980 \\
\hline Female (ref. = male) & $-0.022(0.033)$ & $-0.022(0.033)$ & $-0.022(0.033)$ \\
Age & $-0.001(0.001)$ & $-0.002(0.001)$ & $-0.001(0.001)$ \\
Educational years & $-0.026^{* * *}(0.007)$ & $-0.026^{* * *}(0.007)$ & $-0.026^{* * *}(0.007)$ \\
Resident years & $0.002^{* * *}(0.001)$ & $0.002^{* * *}(0.001)$ & $0.002^{* * *}(0.001)$ \\
Occupational status (ref. = high professionals) & $-0.047(0.123)$ & $-0.048(0.123)$ & $-0.049(0.123)$ \\
Low professionals & $0.033(0.028)$ & $0.033(0.028)$ & $0.033(0.029)$ \\
Self-employed & $0.056(0.056)$ & $0.055(0.056)$ & $0.055(0.056)$ \\
Skilled manual workers & $-0.029(0.053)$ & $-0.029(0.053)$ & $-0.029(0.053)$ \\
Unskilled manual workers & $0.204^{*}(0.115)$ & $0.205^{*}(0.115)$ & $0.206^{*}(0.116)$ \\
Agricultural laborers & $0.019(0.034)$ & $0.019(0.034)$ & $0.018(0.034)$ \\
Unemployed & $-0.008(0.013)$ & $-0.008(0.013)$ & $-0.008(0.013)$ \\
Logincome & $0.573^{* *}(0.277)$ & $0.551^{*}(0.285)$ & $0.532^{*}(0.274)$ \\
MannuPro 2010 & $6.966^{* * *}(1.737)$ & $7.164^{* * *}(1.717)$ & $6.537^{* * *}(1.746)$ \\
ImmigrantPro_2010 & $3.393^{*}(1.915)$ & & \\
KoreanPro_1930 (Instrumented) & & $3.767(2.366)$ & \\
KoreanPro_1955 (Instrumented) & & $0.130(0.153)$ & $5.983^{*}(3.136)$ \\
KoreanPro_1980 (Instrumented) & $0.130(0.153)$ & 3155 & $0.140(0.150)$ \\
Constant & 3155 & 0.018 & 3155 \\
Observations & 0.018 & & 0.018 \\
R-squared & & & \\
\hline & & &
\end{tabular}




\section{Conclusion}

Within the theoretical framework of intergroup contact and ethnic competition theories, numerous studies have investigated how current immigrant size is associated with the xenophobia of native residents (Quillian 1995; Scheepers et al. 2002; Dancygier and Donnelly 2013; Kunovich 2017). To fully understand the origins of native residents' xenophobia, this research aims to establish the synthesis of historical immigrant size and current xenophobia. Using data from Japan, we, for the first time, separated the effects of historical and current immigrant sizes and found that consistent with the previous ethnic competition literature, native residents in regions with a larger immigrant size are more likely to vote against immigration. The core mechanism underlying this result might be related to cultural persistence, as prior negative contact between immigrants and native residents might still exist even after several decades.

This study contributes to the literature in several ways. First, our study is distinct from studies investigating the effects of the increasing immigration size, which only consider immigration during the past 10 years (Coenders and Scheepers 1998). In contrast, we assess a longer period, i.e., from 1920 to 2010, and extend beyond studies investigating relationships between current immigrant sizes and xenophobic attitudes. Second, we attempt to link historical immigrant size to current xenophobia from the perspective of cultural anthropology, which might provide a new perspective enabling social scientists to understand how native residents' xenophobia arises. Third, recently, in keeping with sociologists who have begun to investigate the long-term impact of immigration on current society (Jiménez 2008; Jimenez 2017; Crul 2016), our study also provides some empirical support for cultural persistence regarding attitudes toward immigration. These results overall call for immigration policy makers' attention to the long-term effects of immigration policies.

Our study suffered from certain limitations regarding the measurement of some variables. For example, we only tested how overall historical immigration and Korean and Chinese immigrant sizes are associated with current xenophobia, and determining how other minority groups such as Burakumin and Okinawans and their historical sizes are related to current xenophobia could be beneficial.

Abbreviation

OLS: Ordinary least squares regression

\section{Authors' contributions}

SG developed the theoretical framework, conducted the statistical analyses and wrote the main part of the article. SW wrote some parts of the article and revised the article. The authors read and approved the final manuscript.

\footnotetext{
Authors' information

Shun GONG is an assistant professor at Institute of Sociology, Chinese Academy of Social Sciences. His research focuses on immigration and social attitude issues. Additional research interests include family and education. Part of his work has been published in the International Migration and Chinese Sociological Review Journals. Senhu WANG is an Assistant Professor of Sociology at the National University of Singapore. He holds a PhD in Sociology from the University of Cambridge. His research focuses on immigration, employment, public health, and social inequalities. His work has been published in Social Science \& Medicine, International Migration Review, Population Space and Place, Work Employment and Society, Sex Roles etc.
} 


\section{Competing interests}

We acknowledge we do not have any financial interest or benefit that has arisen from the direct application of our research.

\section{Author details}

'Institute of Sociology, Chinese Academy of Social Sciences, 5 Jianguomennei Street, Dongcheng District, Beijing 100732, China. ${ }^{2}$ Department of Sociology, University of Cambridge, 16 Mill Lane, Cambridge CB2 1SB, UK.

Received: 6 January 2020 Accepted: 29 October 2020

Published online: 04 January 2021

\section{References}

Abbott, Andrew. 2005. The historicality of individuals. Social Science History 29 (1): 1-13. https://doi.org/10.1215/ 01455532-29-1-1.

Acharya, Avidit, Matthew Blackwell, and Maya Sen. 2016. The political legacy of American slavery. The Journal of Politics 78 (3): 621-641. https://doi.org/10.1086/686631.

Allport, Gordon M. 1954. The nature of prejudice. Cambridge: Addison-Wesley.

Araragi, Shinzou. 2008. Nihon Teikoku Wo Meguru Jinkou Idou no Kokusaigaku (immigration during Japan's Imperial period). Tokyo: Fuji Shuppan.

Bisin, Alberto, and Thierry Verdier. 2000. 'Beyond the melting pot': Cultural transmission, marriage, and the evolution of ethnic and religious traits. Quarterly Journal of Economics 115 (3): 955-988. https://doi.org/10.1162/003355300554953.

Blumer, Herbert. 1958. Race prejudice as a sense of group position. The Pacific Sociological Review 1 (1): 3-7. https://doi.org/ $10.2307 / 1388607$

Bonacich, Edna. 1972. A theory of ethnic antagonism: The split labor market. American Sociological Review 37 (5): 547-559. https://doi.org/10.2307/2093450.

Boyd, Robert, and J. Petter Richerson. 1985. Culture and the evolutionary process. Chicago: The University of Chicago Press.

Chung, Erin Aeran. 2010. Immigration and citizenship in Japan. Immigration and citizenship in Japan. Cambridge: Cambridge University Press. https://doi.org/10.1017/CBO9780511711855.

Coenders, Marcel, and Peer Scheepers. 1998. Support for ethnic discrimination in the Netherlands 1979-1993: Effects of period, cohort, and individual characteristics. European Sociological Review 14 (4): 405-422. https://doi.org/10.1093/ oxfordjournals.esr.a018247.

Cornelius, Wayne A., and Takeyuki Tsuda. 2004. Japan: Government policy, immigrant reality. In Controlling immigration: A global perspective, ed. Cornelius, A. Wayne Tsuda, Martin Takeyuki, and L. Philip Hollifield, 2nd ed. Plao Alto: Stanford University Press.

Crul, Maurice. 2016. Super-diversity vs. assimilation: How complex diversity in majority-minority cities challenges the assumptions of assimilation. Journal of Ethnic and Migration Studies. https://doi.org/10.1080/1369183X.2015.1061425.

Dancygier, Rafaela M., and Michael J. Donnelly. 2013. Sectoral economies, economic contexts, and attitudes toward immigration. Journal of Politics 75 (1): 17-35. https://doi.org/10.1017/S0022381612000849.

Doeringer, Peter B. and Piore, Michael J. 1985. Internal Labor Markets and Manpower Analysis. London: Routledge.

Erikson, Robert, John H. Goldthorpe, and Lucienne Portocarero. 1979. Intergenerational class mobility in three Western European societies: England, France and Sweden. The British Journal of Sociology 30 (4): 415-441. https://doi.org/10.2307/ 589632.

Fukuda, Yasunori. 1993. Lives of young Koreans in Japan. Tokyo: Chuko Shinsho.

Giuliano, Paola, and Nathan Nunn. 2017. Understanding cultural persistence and change. National Bureau of Economic Research. https://doi.org/10.3386/w23617.

Gong, Shun. 2018. Are the consequences of experiencing discrimination the same for immigrants of differing socioeconomic status in Japan? International Migration 56 (2): 37-55. https://doi.org/10.1111/imig.12370.

Green, David, and Yoshihiko Kadoya. 2015. Contact and threat : Factors affecting views on increasing immigration in Japan. Politics \& Policy 43 (1): 59-93. https://doi.org/10.1111/polp.12002/abstract.

Harold, Joshua, and Eric Fong. 2017. Mobilizing memory: Collective memory schemas and the social boundaries of Jews in Toronto. Ethnic and Racial Studies. https://doi.org/10.1080/01419870.2017.1344719.

Hiers, Wesley, Thomas Soehl, and Andreas Wimmer. 2017. National trauma and the fear of foreigners: How past geopolitical threat heightens anti-immigration sentiment today. Social Forces 96 (1): 361-388. https://doi.org/10.1093/sf/sox045.

Holbrow, Hilary J., and Kikuko Nagayoshi. 2016. Economic integration of skilled migrants in Japan: The role of employment practices. International Migration Review: 1-29. https://doi.org/10.1111/imre.12295.

Jimenez, Tomás. 2017. The other side of assimilation how immigrants are changing American life. Oakland: University of California Press.

Jiménez, Tomás R. 2008. Mexican immigrant replenishment and the continuing significance of ethnicity and race. American Journal of Sociology 113 (6): 1527-1567. https://doi.org/10.1086/587151.

Kashiwazaki, Chikako, and Tsuneo Akaha. 2006. Japanese immmigration policy: Responding to conflicting pressures The Online Journal of Migration Policy Institute November.

Kondo, Atsushi. 2002. Development of immigration policy in Japan. Asian and Pacific Migration Journal 11 (4): 415-436.

Kunovich, Robert M. 2002. Social structural sources of anti-immigrant prejudice in Europe. International Journal of Sociology 32 (1): 39-57. https://doi.org/10.1080/15579336.2002.11770243.

Kunovich, Robert M. 2017. Labour market competition and immigration attitudes in an established gateway. Ethnic and Racial Studies 40 (11): 1961-1980. https://doi.org/10.1080/01419870.2016.1237670.

Levitt, Peggy, and B. Nadya Jaworsky. 2007. Transnational migration studies: Past developments and future trends. Annual Review of Sociology 33 (1): 129-156. https://doi.org/10.1146/annurev.soc.33.040406.131816.

Lie, John. 2001. Multiethnic Japan. Cambridge: Harvard University Press. https://doi.org/10.1017/CBO9781107415324.004.

Morgan, Stephen L., and Christopher Winship. 2014. Counterfactuals and causal inference: Methods and principles for social research (analytical methods for social research). New York: Cambridge University Press. 
Nunn, Nathan. 2008. The long-term effects of Africa's slave trades.". Quarterly Journal of Economics 123 (1): 139-176. https:// doi.org/10.1162/qjec.2008.123.1.139

Nunn, Nathan. 2009. The importance of history for economic development. Annual Review of Economics 1 (1): 65-92. https:// doi.org/10.1146/annurev.economics.050708.143336.

Pettigrew, Thomas F. 1998. Intergroup contact theory. Annual Review of Psychology 49 (1): 65-85. https://doi.org/10.1146/ annurev.psych.49.1.65.

Putnam, Robert. 2007. E pluribus Unum: Diversity and community in the twenty-first century the 2006 Johan Skytte prize lecture. Scandinavian Political Studies 30 (2): 137-174. https://doi.org/10.1111/j.1467-9477.2007.00176.x.

Quillian, Lincoln. 1995. Prejudice as a response to perceived group threat: Population composition and anti-immigrant and racial prejudice in Europe. American Sociological Review 60 (4): 586. https://doi.org/10.2307/2096296.

Ryang, Sonia. 2002. A long loop: Transmigration of Korean women in Japan. International Migration Review 36 (3): 894-911.

Scheepers, Peer, Mérove Gijsberts, and Marcel Coenders. 2002. Ethnic exclusionism in European countries : Public opposition to civil rights for legal migrants as a response to perceived ethnic threat. European Sociological Review 18 (1): 17-34. https://doi.org/10.1093/esr/18.1.17.

Schneider, Silke L. 2008. Anti-immigrant attitudes in Europe: Outgroup size and perceived ethnic threat. European Sociological Review 24 (1): 53-67. https://doi.org/10.1093/esr/jcm034.

Sherif, M., and C.M. Sherif. 1967. Attitudes as the individual's own categories: The social judgment-involvement approach to attitude and attitude change. In Attitude, ego-involvement, and change, 105-169. Westport: Greenwood Press.

Tajfel, Henri, and John Turner. 1979. An integrative theory of intergroup conflict. In The social psychology of intergroup relations, ed. Willian G. Austin and Stephen Worchel, 33-47. Monterey: Brooks-Cole. https://doi.org/10.1016/S0065$2601(05) 37005-5$.

Takenoshita, Hirohisa. 2013. Labour market Flexibilisation and the disadvantages of immigrant employment: JapaneseBrazilian immigrants in Japan. Journal of Ethnic and Migration Studies 39 (7): 1177-1195. https://doi.org/10.1080/1369183X. 2013.778140.

Tanabe, Shunsuke. 2016. The public opinion poll on internationalization and citizens' political participation survey 2013 report.

Wang, Senhu. 2019a. Cultural and social integration of British immigrants and ethnic minorities: Exploring ethnic and generational differences in gender role attitudes, social networks, neighborhood attachment and work values. Cambridge: University of Cambridge.

Wang, Senhu. 2019b. The role of gender role attitudes and immigrant generation in ethnic minority Women's labor force participation in Britain. Sex Roles 80 (3-4): 234-245. https://doi.org/10.1007/s11199-018-0922-8.

Wang, Senhu, and Rory Coulter. 2019. Exploring ethnic and generational differences in gender role attitudes among immigrant populations in Britain: The role of neighborhood ethnic composition. International Migration Review 53 (4) 1121-1147. https://doi.org/10.1177/0197918318802780.

Wang, Senhu, and Shuanglong Li. 2019. Exploring generational differences of British ethnic minorities in smoking behavior, frequency of alcohol consumption, and dietary style. International Journal of Environmental Research and Public Health 16 (12): 22-41. https://doi.org/10.3390/ijerph16122241.

Wang, Senhu, and Mark Ramsden. 2018. Revisiting the 'parallel lives' thesis: Neighbourhood attachment and residential integration of ethnic minorities in England. Population, Space and Place 24 (8): e2156. https://doi.org/10.1002/psp.2156.

Yan, Yudong, Shuyi Wang, Wanying Zhou, Senhu Wang, and Shun Gong. 2019. Does immigrant generation matter? Reexamining the ethnic density effects on mental health of ethnic minorities in Britain. American Journal of Health Behavior 43 (5): 924-936. https://doi.org/10.5993/AJHB.43.5.5.

\section{Publisher's Note}

Springer Nature remains neutral with regard to jurisdictional claims in published maps and institutional affiliations.

\section{Submit your manuscript to a SpringerOpen ${ }^{\circ}$ journal and benefit from:}

- Convenient online submission

- Rigorous peer review

- Open access: articles freely available online

- High visibility within the field

- Retaining the copyright to your article

Submit your next manuscript at $\boldsymbol{s p r i n g e r o p e n . c o m ~}$ 